\title{
Cinema e contraluz: limiares da repressão na cultura midiática argentina ${ }^{1}$
}

\author{
Márcio Serelle
}

Resumo: Este artigo busca examinar em filmes argentinos (notadamente Valentín, Kamchatka e O segredo dos seus olhos) o procedimento da contraluz, entendido como um modo de composição narrativa em que eventos relacionados a ditaduras e outras formas de repressão movem-se no escuro, porém atuando agudamente sobre a trajetória das personagens. A partir de uma breve recuperação do movimento de internacionalização da cinematografia argentina, que, já em meados de 1980, articula estruturas dramáticas convencionais e denúncia política, pretende-se analisar o modo como parte do cinema deste século representa a violência de estados autoritários. Seja pelo investimento imaginativo, pela metalinguagem ou pela alegoria, essas narrativas renunciam às imagens explícitas da violência dos aparatos repressores e engendram dramaturgias de grande eficácia comunicacional. Coloca-se, assim, em discussão, a capacidade reflexiva desses filmes no que se refere às relações entre o ficcional, o midiático e o social.

Palavras-chave: cinema argentino; autoritarismo; cultura midiática.

Abstract: Cinema and backlighting: on the threshold of repression of Argentine media culture - This paper examines the backlighting technique used in Argentine movies (mainly Valentín, Kamchatka, and The Secret in Their Eyes), seen as a kind of narrative composition in which events related to dictatorships and other forms of repression operate in the dark, but strongly affect the fate of the characters. Starting from a brief overview of the internationalization of the Argentine film industry, which, as early as the mid-1980s, had already articulated conventional dramatic structures and political denunciation, this study analyzes how part of the cinema of this century represents the violence of authoritarian states. Be it through imaginative investment, metalanguage, or allegory, these narratives renounce graphic images of the violence of repressive apparatuses and create dramaturgical compositions of highly effective communication. Thus, this work discusses the reflective capacity of these films as it pertains to the relationship between the fictional, mediatic and social contexts.

Keywords: Argentine cinema; authoritarianism; media culture.

1 Esta é uma versão do texto apresentado ao Grupo de Trabalho Cultura das Mídias, no XXII Encontro Anual da Compós, na Universidade Federal da Bahia, Salvador, de 04 a 07 de junho de 2013. 


\section{Introdução}

Na cinematografia argentina deste século, um conjunto de filmes apresenta um modo de composição narrativa em que eventos sociais traumáticos, relacionados à ditadura e outras formas de autoritarismo, movimentam-se no escuro, porém atuando fortemente sobre a vida das personagens. Essa poética da "contraluz", aqui na acepção do lugar pouco iluminado, perpassa filmes de grande eficácia comunicacional como Valentín (2002), dirigido por Alejandro Agresti; Kamchatka (2002), de Marcelo Piñeyro; e O segredo dos seus olhos (2009), de Juan José Campanella.

Conquanto a natureza polissêmica desses filmes, que se prestam a várias leituras, este artigo objetiva analisar nessas narrativas os aspectos relacionados às formas de representação da violência de estados autoritários, nesse jogo entre ausência e presença, em que esse cinema aciona caminhos para a sensibilização de grandes plateias. Este texto obedece, entretanto, a três movimentos principais: inicialmente, buscamos delinear a noção de contraluz - em meio ao imperativo midiático da violência explícita, hoje e os pontos de coerência entre os filmes estudados; em seguida, recuperamos, ainda que brevemente, à guisa de matriz, as articulações entre estruturas dramáticas convencionais e denúncia política presentes já no processo de internacionalização do cinema argentino, a partir da apertura, na década de 1980; por fim, a análise fílmica leva-nos à reflexão acerca das relações estabelecidas, por essas narrativas, entre o ficcional, o midiático e o social, assim como sobre a potência que elas possuem, ao se constituírem do elíptico e do implícito, para deslocar o olhar do espectador.

\section{Ideia de contraluz}

A percepção de um evento posto fora de cena que, no entanto, atua agudamente sobre a representação é compartilhada pelos espectadores desde as origens do drama. Sabe-se que os gregos não levavam ao proscênio o explícito das atrocidades, que ocorriam atrás de uma das três portas previstas na ordem espacial do espetáculo. Por razões éticas e convenções estéticas, eventos relacionados à violência e ao sexo não eram encenados, isto é, dados a ver diretamente. Como recupera Black (2002), as ações levadas ao palco limitavam-se à periferia da tragédia, aos acontecimentos que antecediam e que se seguiam aos momentos-chave de horror. Esses preceitos conformaram uma linhagem artística humanista que sublimou a crueldade de rituais e execuções (testemunhadas cotidianamente), sem, contudo, apagar a violência, que permanece latente, como algo que, de fora da moldura, pressiona e desencanta a vida retratada.

Essa noção de representação evocou, assim, cenas primitivas e ritualísticas das quais possivelmente despontou o próprio teatro, mas também demandou certo grau de afastamento delas, que implicava a consciência, de que falava Aristóteles (1981), 
de se ver o imitado. Esse processo, que é também o de socialização da cultura ocidental, como assinala Black (2002), acabou por deslocar, principalmente a partir do Iluminismo europeu, o termo estética para mais próximo da contemplação, por meio, no caso da narrativa, de artifícios mediadores como o próprio narrador, o flashback ou a mise en abyme.

No entanto, como argumenta esse mesmo autor, em face do atual impulso gráfico da cultura fílmica contemporânea ${ }^{2}$, com sua ânsia de mostrar tudo, em parte facultada pelas tecnologias de registro mais recentes, tal linhagem torna-se secundária no cinema, hoje, dando a vez a estéticas da crueldade e da sensação, que se tornam imperativas. Para Gomes (2012, p. 72), diante do paroxismo das imagens violentas, assistimos, na primeira década do XXI, a um "realismo brutal" construído por narrativas da cultura midiática e de determinada literatura que evidenciam o espaço urbano do crime, com seus corpos sanguinolentos, torturados e mutilados. De modo resumido, a tese de Gomes (2012), a partir das contribuições do filósofo Clément Rosset (2002), é a de que a crueldade atingida pelo explícito na cultura midiática quase sempre abdica de complexidade, pois, seja pelo hiperrealismo que deseja abalar o espectador, seja, em alguns casos, pela cilada moral, termina por tamponar a brutalidade de nossa natureza trágica e do caráter inelutável do próprio real, quando despojado de seus semblantes.

Pelo menos um dos pontos levantados acerca dessa explicitação da violência nas telas mantém os contornos de sua dificuldade: a questão dos modos como se relacionam sociedade e mundos ficcionais no que se refere à crueldade e o horror. Para além do imediatismo de Black (2002), que vislumbra na patologia de atiradores norteamericanos, como os de Columbine, o efeito de looping, em que o massacre na tela transborda para o mundo real e vice-versa, Gomes (2012, p. 84) sugere a possibilidade de "reciclagem" da violência por certo tipo de ficção, como Contra todos (2004), de Roberto Moreira, capaz de apontar "saídas" ao produzir narrativas de uma crueza que recusa-se justamente à completude e a "imagens ilusórias e efêmeras do êxito" (GOMES, 2012).

Se esse imperativo gráfico é perceptível, hoje, nas telas, ele não aniquila, como dissemos, uma poética de contraluz, mas, antes, evidencia-a, como nos filmes argentinos aqui selecionados, que resistem em colocar no centro determinadas violências históricas, sem ocultá-las por completo. Ao tratar de eventos relacionados às ditaduras e outras formas de repressão, que remetem também, mas não só, aos corpos violados, esses filmes argentinos, ainda que possam usar de imagens explícitas de crueldade - destacadamente O segredo dos seus olhos -, não encenam diretamente o horror histórico, dando-lhe,

2 O termo "gráfico", que será utilizado no decorrer deste artigo, e a expressão "cultura fílmica" usados por Black (2002) merecem considerações. "Gráfico" é tradução nossa direta do adjetivo graphic, que, em inglês, designa, em uma de suas acepções, algo que é "claro", "visível" e "bem detalhado", de modo que muitas vezes leva a imagens explícitas e intoleráveis. A raiz, como no português, é latina, vem de graphicus, que significa "perfeito" e "completo". Já "cultura fílmica" diz respeito não somente ao cinematográfico, mas a uma cultura originada, segundo Black (idem), na tendência do século XX para o registro audiovisual total. Dessa forma, a "cultura fílmica" entrelaçaria o próprio cinema, videogames, produção caseira para youtube, imagens de satélite e de câmeras de segurança, reportagem televisiva etc. 
assim, outras formas de resposta e ressonância. Movendo-se no limite ou fora da cena, essas formas de violência afetam profundamente as personagens, que, na superfície do enredo, agem em dramas domésticos ou em thrillers policiais. De certa forma, esse artifício pode ser comparado, no cotejo com imagens literárias, à forma do enquadramento do conto moderno que, segundo Ricardo Piglia, opera por obliteração: "a história é construída com o não-dito, com o subentendido e a alusão" (PIGLIA, 2004, p. 92). Nesse sentido, segundo o autor, o princípio do iceberg formulado por Hemingway, em que a magnitude e a gravidade da base encontram-se sempre fora da linha do olhar, "é a primeira síntese desse processo de transformação" (PIGLIA, 2004, p. 91), sensível em contistas como Tchekhov e Mansfield.

O modo de composição fílmica pela contraluz, à maneira dessa estratégia do conto moderno, caracteriza o conjunto de filmes delimitado aqui. Se o corpus não representa toda uma dicção do cinema argentino, dada a multiplicidade da produção cinematográfica daquele país, que também coloca em relevo, por exemplo, obras de violência explícita como Abutres (2010), de Pablo Trapero, podemos afirmar que esses filmes estabelecem determinada coerência principalmente pelo modo como narram as ações de mecanismos repressivos referentes ao autoritarismo. Na Argentina em 1966 e novamente em 1976, os regimes tiveram como um dos eixos centrais a força armada e coercitiva, que, sob o discurso da segurança nacional, implantaram "padrões de comando altamente autoritários e repressivos em quase todos os contextos da vida cotidiana" (O’DONNELL, 1986, p.55). Valentín, Kamchatka e O segredo dos seus olhos tratam, de acordo com seus respectivos contextos, desses e de outros aparatos repressores que, embora quase sempre permaneçam fora de cena, são sensíveis na trama em que se debatem as personagens.

Esses filmes caracterizam-se, ainda, pela presença de diretores argentinos de incursão internacional, por vezes hollywoodiana ou em seriados televisivos norte-americanos (a exemplo de Agresti e Campanella); por um elenco que conforma um certo star system de língua espanhola (Ricardo Darín, Carmen Maura, Cecilia Roth, entre outros); por se inserirem na experiência industrial, não dispensando, portanto, as amarras das estruturas dramáticas; por mobilizarem público composto, grosso modo, pela classe média argentina e, em geral, por plateias globais, interessadas em outros "filmes estrangeiros" (ou seja, não hollywoodianos ou não falados em língua inglesa).

Com risco de serem taxadas como "digestivas" ${ }^{3}$ ou de serem consideradas insuficientemente complexas, por integrarem sem arestas a cultura midiática, essas narrativas atendem a parte da expectativa internacional acerca do que seria uma trama ou uma situação argentina (ANDERMANN, 2012), delineada por abordagens do autoritarismo. Desde a década de 80, observam-se esforços de internacionalização do cinema argentino, por meio da junção por vezes bastante criticada entre melodrama e política.

3 O termo foi usado por Canclini (2008, p. 89) para se referir a Nove rainhas (2000), de Fabián Bielinsky, e $O$ filho da noiva (2001), de Campanella, filmes que, segundo ele, fazem "concessões" e se utilizam de "piadas vendáveis", assim como "tantos [filmes] mexicanos e brasileiros entusiasmados com esse mesmo recurso". 
Portanto, o problema que devemos contornar diz respeito também a essas clivagens entre "filme industrial" e "filme independente", entre "cinema de entretenimento" e "cinema de qualidade" (considerado, por vezes, como aquele de refinamento estético e identificado com questões políticas), entre o "mainstream" e o "experimental", que remetem persistentemente a outras cisões, que parecem querer ressuscitar a separação entre alto e baixo, que os pós-modernistas julgavam abolida.

\section{Pedagogia do desvelamento}

Em 1984, ano que se segue ao colapso do regime militar na Argentina e à eleição de Raul Alfonsín (outubro de 1983), dos 26 filmes produzidos, 16 focaram o período de repressão, tendência que permaneceu até o final de 1989, quando da guinada neoliberal de Menem, caracterizada por uma aliança entre estado e canais privados de televisão (FALICOV, 2000). A metáfora mais utilizada para o período da apertura, em que o cinema torna-se importante pilar da cultura argentina, é o da sala escura de projeção transformada em confessionário ${ }^{4}$. Essa voga dos testemunhos foi também estimulada politicamente por meio de um estado que subsidiou "um cinema que retornasse aos aspectos mais sombrios do passado ditatorial: o sequestro, tortura e assassinato de dezenas de milhares de cidadãos" (ANDERMANN, 2012, p. 3) (tradução nossa) $)^{5}$.

O que nos interessa mais de perto, contudo, são as articulações entre drama e relato acerca da repressão que já aparecem em um dos filmes argentinos de maior visibilidade do período, A história oficial (1985), de Luiz Puenzo. Nessa narrativa, a ditadura assume a frente da cena, ainda que no plano da intimidade do lar, sob o ponto de vista burguês. A protagonista é uma professora de História, Alicia, que pertence à classe média conservadora e conivente - seja pela ignorância cômoda, seja pelo oportunismo financeiro -, com o governo militar. Alicia toma, aos poucos, conhecimento das atrocidades do regime e descobre que sua filha adotiva, Gaby, pode ser uma das crianças sequestradas de pais ativistas políticos presos e assassinados por militares.

De extensa fortuna crítica, A história oficial geralmente é descrita como filme típico dessa conjuntura, que, visando grandes plateias, instituiu uma pedagogia do desvelamento, na perspectiva conveniente de uma classe média "desconhecedora" do horror em que a sociedade estava inserida. Uma das críticas recorrentes ao filme é a de privilegiar o drama particular burguês às causas coletivas. Para Falicov (2001), a narrativa segue as linhas de um bildungsroman, em que Alicia decide, após o conhecimento da circunstância, buscar as origens da filha adotiva e, ao final, confrontar o marido corrupto. Logo, "o coletivo é subestimado, assim como as verdadeiras heroínas do filme, as Madres [da Plaza de Mayo],

4 A imagem aparece primeiramente na crítica de Patricia Aufderheid (1986), sendo evocada nos estudos de Falicov (2000, 2001) e no de Andermann (2012).

5 No original: "(...) a cinema that returned to the darkest aspects of the dictatorial past: the abduction, torture and assassination of tens of thousands of citizens". 
e, de forma oposta, a tomada de consciência do indivíduo é enaltecida" (FALICOV, 2001, p. 131) (tradução nossa) ${ }^{6}$. Xavier reconhece que $A$ história oficial possui poder comunicacional e determinado alcance na discussão da conjuntura nacional, mas ressalva o modo como a narrativa se apoia no melodramático, o que, segundo ele, causaria, em suas formas de afecção, a redução do "horizonte de compreensão social" (XAVIER, 2003, p. 141).

Embora essas análises sejam pertinentes, é justo argumentar que a consciência da limitação do próprio olhar burguês não escapa de todo à narrativa fílmica, como na cena em que o professor esquerdista de Literatura, Benitez, encontra-se com Alicia clandestinamente num café e a ironiza: "Como é comovente a culpa burguesa". O encontro da Literatura com a História (oficial) remete a um diálogo entre séries discursivas que demanda movimento a contrapelo, que jogue luz, pelas frestas do ficcional, sobre o modo como determinada cultura, desde seu passado colonial, constrói-se a partir das narrativas dos vencedores.

As representações da violência em A história oficial não se dão por meio de imagens imediatas da tortura militar. O horror revela-se, inicialmente, no relato oral da amiga de Alicia, Ana, sequestrada e violentada pelo Regime, ratificando, também no ficcional, aquilo que Rancière (2010) vislumbra criticamente como a virtude dada à palavra do testemunho, que, na sua incompletude, evitaria a emergência de imagens gráficas e intoleráveis porque transformadoras do evento em espetáculo. Seguem-se, no filme, outras alusões à tortura militar, presentes, por exemplo, nas brincadeiras de criança, que "arrombam" portas com os pés e entram nos quartos "fuzilando" todos com suas armas de brinquedo, ou no irrompimento da violência doméstica no confronto final do casal, cena cruel em que os dedos de Alicia são prensados na porta. A renúncia a imagens explícitas da violência cometida pelo regime talvez não seja, contudo, em sentido amplo, uma renúncia ao espetáculo, pois o filme se utiliza de outros recursos para alcançar grandes plateias, o que, de certo modo, torna-se uma matriz para a cinematografia argentina.

\section{Da dupla natureza dos escapistas}

Delineado, ainda que brevemente, esse espaço cinematográfico argentino, que urde recorrentemente eventos sociais traumáticos em estruturas dramáticas convencionais, pelo menos desde meados de 1980, observamos que Valentín e Kamchatka, que compartilham o ponto de vista da criança, narram a partir desses códigos fílmicos. Essas obras adotam a perspectiva dos filhos daqueles que foram perseguidos por aparatos repressores do passado. A violência do contexto, de acordo com Andermann (2012), é, assim, mediada pelo investimento criativo dos protagonistas.

Embora remetam a contextos diferentes - Valentín ao período da ditadura militar entre 1966 e 1973; e Kamchatka ao regime pós 1976 -, ambos os filmes são perpassados, em seu imaginário, pelas polarizações da Guerra Fria. Em Valentín, o histórico é composto

6 No original: "The collective is underplayed, such as the true heroines of the film, the Madres, and instead, the individual's coming to consciousness is lauded". 
nos detalhes, que situam a narrativa entre 1967 e 1969. Primeiramente, assistimos ao sermão de um padre esquerdista em homenagem a Che Guevara, "assassinado violentamente, há alguns dias, na selva boliviana"; no desfecho, somos informados da chegada do homem à lua. "Armstrong passou-me a perna", diz-nos a criança, com o misto de ingenuidade e agudeza que compõe a personagem. Desde sua apresentação, Valentín fala-nos de sua mirada estrábica ou dos problemas acerca do "ângulo", que podem impedi-lo de ser astronauta, o que indica as possíveis distorções no ponto de vista da narrativa.

O abandono ou desaparecimento da mãe de Valentín, que em algumas das versões dos familiares da criança é descrita como uma judia "corrompida", constrói a intolerância e a violência sociais. No plano à vista, contudo, assistimos, de modo empático, a essa ausência materna ser encoberta de diversos modos, como na relação carinhosa entre Valentín e o tio. Nas cenas finais, após a morte da avó com quem vivia, Valentín é chamado por um estranho a um café e recebe um presente que teria sido enviado por sua mãe. No diálogo, que se dá em planos fechados, o estranho, que teria sido companheiro da mãe de Valentín, nega que ela tenha abandonado a criança, mas que foi forçada a desaparecer, devido a um tipo de repressão não explicitado, mas que possivelmente diz respeito à escalada, à época, do antissemitismo na Argentina, em conjuntura autoritária. O estranho continua o diálogo com frases desconexas como "Ela ficou muito mal", "Quando digo muito mal...", "Eles ficaram em cima, sabe?", "Que dava medo sair de casa." Valentín, abalado, pede ao homem que pare - "basta" - e passa a falar sobre sua vontade de se encontrar com a mãe. Assistimos, então, ao desespero desse estranho, que é interrompido pela tela escura e silenciosa. Em seguida, Valentín, já, na aparência, recuperado emocionalmente, arquiteta, pelo telefone, um encontro entre seu vizinho judeu, com quem aprendia música às escondidas, e Letícia, ex-namorada do pai e possivelmente também de família judia, que passam a formar um casal que o apadrinha. A sintaxe narrativa opõe, assim, uma situação à outra, com fechamento melodioso.

O final feliz recende, então, a escapismo, assim como as alusões ao lunar que permeiam o filme. No entanto, seria forçoso não reconhecer que, a despeito do conforto oferecido ao espectador, a violência histórica, que permanece obscura, ressoa fortemente na trama e no próprio destino de Valentín. A recusa da criança em saber detalhes sobre o destino de sua mãe é menos uma falta que uma opção dela pela ignorância como forma de suportar o horror. Mesmo com a vontade de resolução presente nessa narrativa, o trágico desponta entre nossa consciência dos eventos, ainda que eles não estejam às claras, e o modo como a personagem estrábica tateia em seu cotidiano.

A imagem do escapista é retomada em Kamchatka, que propõe pelo menos dois sentidos a ela: o de desvio pelo espetáculo e o de fugir ao domínio do regime, ou seja, noções de entretenimento e resistência. O filme é narrado por um menino de 10 anos que, sem a completa consciência do golpe militar de 1976, tem sua vida redirecionada pela ditadura. Obrigado a mudar-se com a família para uma finca, o menino adota 
na clandestinidade o nome de Harry, em homenagem a Harry Houdini, o "escapista", que ele conhece por meio de um livro, encontrado na nova casa, que descreve a arte desse performer radicado nos Estados Unidos, famoso por conseguir se livrar de correntes e cadeados. Seu pai, advogado de diretos humanos perseguido pelo regime militar, adota o nome de David Vincent, personagem da série de ficção científica de televisão norteamericana, Os invasores.

Em Kamchatka, o ideológico não é demonstrado de maneira fácil pela repulsa à cultura de massa de origem norte-americana. Os produtos dela, notadamente a série televisiva, atuam como universos mediadores das relações entre filho e pai ativista. Esse gosto pelo midiático no universo intradiegético desdobra-se nas próprias escolhas cinematográficas do filme, em seu encadeamento e ritmo narrativos.

O local da resistência é, contudo, Kamchatka, a península do extremo leste da então União Soviética que, no jogo de tabuleiro (T.E.G.7), novamente entre pai e filho, suporta os constantes assaltos. Como uma espécie de Leningrado na Segunda Guerra, Kamchatka, evocada no final do filme como signo da determinação e da persistência, marca a posição geográfica e ideológica daquela utopia. Ao lúdico e ao intertextual, entrelaçam-se as rotas de fuga ensinadas às crianças, os nomes dos companheiros do pai que vão sendo sequestrados, as conversas que se dão fora de quadro e, assim, do entendimento da criança. A ironia trágica entre a inocência, aos poucos perdida, na perspectiva da criança, e o conhecimento mais contextual do espectador é, como em Valentín, o efeito maior da contraluz dessa narrativa.

\section{A persistência do cárcere}

As cenas gráficas de $O$ segredo de seus olhos, como a nudez frontal em contexto de pulsão aniquiladora e não de vida, e, principalmente, o cadáver ensanguentado e violado da bela jovem Liliana Coloto, desnudo e caído ao pé da cama, são tramadas em um thriller policial que, pelos holofotes do espetáculo, assombreia a violência política que o subjaz, forjando, assim, sua contraluz. Em consonância com as rotinas narrativas da cultura midiática hegemônica, O segredo dos seus olhos apresenta, no entanto, consciência reflexiva acerca do franco voyeurismo. O próprio encontro de Benjamín Espósito com o corpo de Coloto, que evoca o angelical e a morte, dá-se no conflito entre o sedutor e o abjeto. O local do crime está apinhado de oficiais que espiam o corpo da jovem, atirada no chão. Espósito explora o quarto, as fotografias do casal, mas seu olhar é sempre atraído para o cadáver, até que um legista o cobre com um pano. Embora não seja nosso objetivo fazer uma leitura comparada entre filme e romance, convém assinalar que a cumplicidade sórdida de olhares, que, no caso do cinematográfico, envolve também o espectador seduzido pela violência no obscurecimento dos limites morais, é ainda

7 Em espanhol, Táctica y Estrategia para la Guerra. No Brasil, War. 
mais explorada na obra de Eduardo Sacheri, La pregunta de sus ojos, que deu origem ao filme. No episódio da descoberta do assassino pelo exame do álbum de fotografia da jovem Coloto, Espósito omite parte de seu raciocínio na explicação que dá ao delegado sobre a identificação do criminoso. "O que não disse a Báez foi que, se reparei nesse jeito de olhar, era porque também havia esquadrinhado outra mulher do mesmo modo" (SACHERI, 2011, p. 83), confessa ao leitor, referindo-se à atração que sentia por Hastings. Temos, assim, nesse diálogo entre obras, uma série de olhares sobrepostos e seduzidos: o do assassino Gómez, o dos policiais, o de Espósito, o do espectador-leitor.

O filme é também a história de uma escritura. A cena em que Benjamín Espósito, perseguido por agentes do regime, é forçado a partir para Jujuy abre a narrativa e retorna, mais nítida, na parte final, como palimpsestos de um romance. A versão de abertura sequencia os olhos verdes de Irene Hasting, Espósito carregando a mala em direção ao trem e os passantes como vultos fantasmáticos, sob a melodia triste de um piano. Hastings corre desesperadamente na gare até conseguir sobrepor, no vidro da janela, suas mãos às de Espósito, mas, quando o trem parte e avança, ela fica às lágrimas, na estação. A segunda versão desse episódio é seguida por uma presentificação do tempo fílmico, em que a própria Hasting lê, em primeira mão, o "rascunho" do livro. Numa breve discussão sobre imaginação, Hasting julga a cena inverossímil mesmo para um romance e diz: "Se foi assim, por que não me levou com você?".

A metalinguagem e a ironia ao que seria um acento melodramático do mau escritor convivem, no filme, com a ação e o enigma decifrado, em remate palatável, como na porta que, no encerramento, é finalmente fechada para o desvelamento dos segredos do casal, porém fora do alcance do espectador. Pensemos, ainda, na atratividade narrativa e midiática da cena de perseguição ao assassino no estádio de futebol; do método dedutivo do ajudante Sandoval ou proposto recorrentemente ao próprio espectador; da elucidação final do destino do assassino.

Uma das reviravoltas caras a esse thriller impõe-se pelo fundo político referente à ditadura de 1976. Gómez é libertado para integrar um grupo de extermínio, ligado a militares, que assassina Sandoval e força Espósito ao exílio. A nota política histórica acaba, assim, por alegorizar-se, na produção de um outro sentido para o thriller, com observação acerca de tensões democráticas contemporâneas. Segundo Campanella, a visão do romancista e roteirista do filme foi "respeitada", pois a obra possui "a preocupação única de mostrar que o totalitarismo pode aparecer mesmo durante uma gestão democrática, sem militares no poder" (CAMPANELLA, 2012, p. 1).

Embora o termo "totalitarismo", usado por Campanella, não designe apropriadamente o regime militar argentino, ele parece evocar a condição do domínio total sobre a vida, que aparece no destino dado a Gómez, mantido em cativeiro há décadas por Morales, em sítio afastado. Essa evocação do pensamento totalitário e do "concentracionário" - 
que, como analisa criticamente Sarlo (2007), surge também em buscas por interpretação do horror militar argentino ${ }^{8}$ - remete-nos ao aniquilamento do humano, degradado física e psicologicamente. Gómez, alquebrado e envelhecido, suplica, de sua "jaula", apenas uma palavra que comprove sua humanidade. Porém, em face da revelação do sequestro, do cárcere e da tortura do silêncio, Morales confronta Espósito: "Você disse 'prisão perpétua'". Ao final, recolhemo-nos, espectadores e investigador, sigilosos e coniventes com o justiçamento. A exposição do modo como as audiências de uma classe média internacionalizada tornam-se "cúmplices" dessa crueldade é um dos méritos do filme. A atualização do "porão" e da violência do silêncio indica que o horror é tão difuso quanto atemporal. Essa leitura implica, porém, lidar com o inconveniente da despolitização, pois a ditadura dilui-se no filme como uma entre as muitas formas do Mal radical, sem que aspectos ideológicos sejam discutidos.

Ainda que trabalhemos com a hipótese de essa alegoria ser intencionada, convém assinalar que a narrativa articula-se pela alternância temporal e, como dissemos, pelo imaginativo, por vezes incerto, na recuperação do passado, abrindo, assim, uma outra face alegórica. Na memória do particular e do histórico, aqui imbricados pela trama, Morales e a própria Argentina, como nação, ficam presos, atados ao horror que foi infligido a eles. Sem a possibilidade de uma verdadeira anistia, é preciso suportar essa outra forma cruel de encarceramento no tempo passado. O desenlace só é parcialmente possível na decifração do crime ou, como em Valentín, no modelo empático do melodrama, no plano da sugerida felicidade do casal Espósito-Hasting, que, na cena mencionada, fecha a porta e encerra o filme.

\section{Considerações finais}

Esse jogo cinematográfico da ausência e da presença, que reelabora constantemente tópicas da repressão na relação com trajetórias individuais e dramas familiares, delineou aspectos para identificação e reconhecimento dessa cultura midiática produzida a partir da Argentina, internacionalizando-a. A projeção desse cinema, como dissemos, foi articulada já na política cultural da apertura, visando, como observa Falicov (2001), a construção da imagem de um país já livre da ditadura e que passava a narrar seus traumas a partir do "gênero" latino-americano mais amplo do período, o testimonio. Essa cinematografia estabeleceu-se, contudo, a partir de um conjunto de filmes que Xavier identifica como de países periféricos e "dispostos a tocar nas feridas do social sem perder audiência", no alinhamento com o "novo regime internacional de padronização de roteiros" (XAVIER, 2003, P. 141).

Valentín, Kamchatka e $O$ segredo dos seus olhos não são filmes políticos se considerados à luz de um dos significados da palavra propostos por Rancière (2012) para qualificar assim uma ficção, ou seja, aquele que remete a uma operação artística,

8 Ver, a esse respeito, a leitura que Sarlo (2007) faz, em Tempo passado, da obra de Pilar Calveiro, Poder y desaparición: los campos de concentración en Argentina. 
de paradigma brechtiano, em que a arte privilegia a forma quebradiça e a exposição de tensões que substituem as continuidades próprias do modelo narrativo industrial. Tampouco, quanto à tematização, não há (e nem poderia haver, dado o mecanismo da contraluz), nesses filmes, exposição às claras do horror político e de seus aparatos autoritários, ainda que as injustiças se façam sentir na vida das personagens duplamente enredadas: na narrativa e na força histórica. De comunicação eficaz, como assinala Xavier (2003), esses filmes, adequados ao cosmopolitismo das dramaturgias, são limitados, sob determinada perspectiva, no que se refere à sua incapacidade de aprofundamento em questões ideológicas que notadamente marcaram esses eventos.

Reconhecidas essas "insuficiências" políticas, pensemos, contudo, na forma positiva como esse cinema pode provocar certo deslocamento do olhar, ao renunciar ao caráter gráfico de determinado horror e revelar, por meio dessa que é fundamentalmente uma arte da visibilidade dos corpos, a intangibilidade e, ao mesmo tempo, a espessura de uma brutalidade (presente nas ditaduras, no antissemitismo ou na guerra, como a das Malvinas, em Um conto chinês) que acaba por curvar esses sujeitos ficcionais. O que vemos são gestos e atitudes dessas criaturas aparentes, que, imersas, debatem-se na invisibilidade de um processo, entre determinações, arbítrios e vontades.

Márcio Serelle é professor do Programa de Pós-Graduação em Comunicação Social, Interações Midiáticas, da PUCMG e pesquisador do CNPq. marcio.serelle@gmail.com

\section{Referências}

ANDERMANN, Jens. New Argentine cinema. London: I. B. Taurus, 2012.

ARISTÓTELES. Poética. São Paulo: Ars Poetica Editora, 1981.

AUFDERHEID, Patricia. Awake Argentina!. In: Film comment. Vol. 22, no.2, 1986. p. 54.

BLACK, Joel. The reality effect - film culture and the graphic imperative. New York: Routledge, 2002.

CAMPANELLA, Juan José. Campanella às claras. O Globo. Rio de Janeiro. 17 de agosto de 2012. Segundo Caderno, p. 1 Entrevista concedida a Rodrigo Fonseca.

CANCLINI, Néstor García. Latino-americanos à procura de um lugar neste século. São Paulo: Iluminuras, 2008.

FALICOV, Tamara. Argentina's blockbuster movies and the politics of culture under neoliberalism, 1989-98. In: Media, culture \& society. Vol. 22, 2000. pp. 327-342. 
GOMES, Renato Cordeiro. Por um realismo brutal e cruel. In: MARGATO, Izabel e GOMES, Renato Cordeiro (Org.). Novos realismos. Belo Horizonte: Editora UFMG, 2012. pp. 71-89.

O’DONNELL, Guillermo. Contrapontos: autoritarismo e democratização. São Paulo: Vértice, 1986. PIGLIA, Ricardo. Formas breves. São Paulo: Companhia das Letras, 2004.

RANCIÈRE, Jacques. O espectador emancipado. Lisboa: Orfeu Negro, 2010.

. As distâncias do cinema. Rio de Janeiro: Contraponto, 2012.

ROSSET, Clément. O princípio da crueldade. 2a ${ }^{\text {a }}$ ed. Rio de Janeiro: Rocco, 2002.

SACHERI, Eduardo. O segredo dos seus olhos. Rio de Janeiro: Objetiva: 2011.

SARLO, Beatriz. Tempo passado. São Paulo: Companhia das Letras; Belo Horizonte: UFMG, 2007.

XAVIER, Ismail. O olhar e a cena. São Paulo: Cosac \& Naif, 2003.

\section{Filmografia}

A história oficial/La historia oficial (Luiz Puenzo, Argentina, 1985, 112', ficção)

Abutres/Carancho (Pablo Trapero, Argentina/Chile/França/Coréia do Sul, 2010, 107', ficção)

Contra todos (Roberto Moreira, Brasil, 2004, 96', ficção)

Kamchatka (Marcelo Piñeyro, Argentina/Espanha, 2002, 105', ficção).

Nove rainhas/Nueve reinas (Fabián Bielinsky, Argentina, 2000, 115', ficção)

O filho da noiva/El hijo de la novia (Juan José Campanella, Argentina/Espanha, 2001, 124', ficção)

O segredo dos seus olhos/El secreto de sus ojos (Juan José Campanella, Argentina, 2009, 127', ficção)

Um conto chinês/Un cuento chino (Sebastián Borensztein, Argentina/Espanha, 2011, 93', ficção)

Valentín (Alejandro Agresti, Argentina/Holanda, 2002, 86', ficção). 